\title{
Examining maintenance care following infliximab salvage therapy for acute severe ulcerative colitis
}

Dean Seah ${ }^{1}$, Matthew C Choy ${ }^{1,2,3}$, Alexandra Gorelik ${ }^{4}$, William R Connell ${ }^{2}$, Miles P Sparrow $^{5,9}$, Daniel Van Langenberg ${ }^{6,9}$, Geoffrey Hebbard ${ }^{7}$, Gregory Moore ${ }^{8,9}$, Peter De Cruz ${ }^{1,3}$

${ }^{1}$ Department of Gastroenterology, Austin Health, Melbourne, Australia ${ }^{2}$ Department of Gastroenterology, St Vincent's Hospital, Melbourne, Australia ${ }^{3}$ Department of Medicine, Austin Academic Centre, University of Melbourne, Melbourne, Australia

${ }^{4}$ Melbourne EpiCentre, Melbourne Health, Melbourne Australia

${ }^{5}$ Department of Gastroenterology, Alfred Health, Melbourne, Australia ${ }^{6}$ Department of Gastroenterology, Eastern Health, Melbourne, Australia ${ }^{7}$ Department of Gastroenterology, Melbourne Health, Melbourne, Australia ${ }^{8}$ Department of Gastroenterology, Monash Health, Melbourne, Australia ${ }^{9}$ Department of Medicine, Monash University

\section{Grant support}

MCC is supported by an Australian Postgraduate Award scholarship from the University of Melbourne.

PDC is supported by a David Bickart Clinician Research Award from the University of Melbourne and Bushell Postdoctoral Award from the Gastroenterological Society of Australia.

\section{Author for correspondence:}

Dr Peter De Cruz

Department of Gastroenterology, Austin Health

145 Studley Road

Heidelberg VIC 3084 Australia

This is the author manuscript accepted for publication and has undergone full peer review but Tel: +613394965353 e copyediting, typesetting, pagination and proofreading process, which

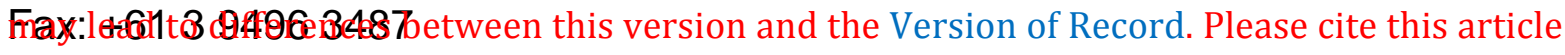

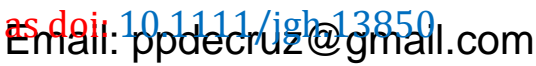




\section{Abbreviations}

UC, Ulcerative Colitis; ASUC, Acute Severe Ulcerative Colitis; IFX, Infliximab; MTX, methotrexate; 5-ASA, 5-aminosalicylate; CRP, C-reactive protein; IBD, Inflammatory Bowel Disease; IQR, Interquartile Range; TNF, Tumour Necrosis Factor

\section{Disclosures}

MCC has received educational support from Ferring, Shire, Janssen, AbbVie, Takeda and Orphan. PDC has received educational support, consulted on advisory boards, and been a speaker at educational symposia sponsored by Ferring, Shire, Janssen, AbbVie, Takeda and Baxter.

\section{Author Contributions}

DS: was involved in study concept and design, acquisition of data; analysis and interpretation of data; drafting of the manuscript and statistical analysis MCC: was involved in study concept and design, acquisition of data; analysis and interpretation of data; drafting of the manuscript and statistical analysis;

AG: was involved in statistical analysis and interpretation of the data WRC, MPS, DVL, GH, GM: were involved in acquisition of data and critical revision of the manuscript;

PDC: was involved in study concept and design, drafting of the manuscript, critical revision of the manuscript for important intellectual content and supervision of the study

\section{Abstract Word Count: 248}

Main Text Word Count: 2670

Preliminary results of this study were in part presented at ECCO 2016 Amsterdam. 


\title{
TITLE
}

\section{Examining maintenance care following infliximab salvage therapy for acute severe ulcerative colitis}

\begin{abstract}
Background and Aims: Data supporting the optimal maintenance drug therapy \& strategy to monitor ongoing response following successful infliximab (IFX) induction, for acute severe ulcerative colitis (ASUC), are limited. We aimed to evaluate maintenance \& monitoring strategies employed in patients post IFX induction therapy.
\end{abstract}

Methods: Patients in 6 Australian tertiary centres treated with IFX for steroidrefractory ASUC between April 2014 \& May 2015 were identified via hospital IBD \& pharmacy databases. Patients were followed-up for 1 year with clinical data over 12 months recorded. Analysis was limited to patient outcomes beyond 3 months.

Results: 41 patients were identified. 5/41 (12\%) patients underwent colectomy within 3 months and 1 patient was lost to follow-up. 6/35 (17\%) of the remaining patients progressed to colectomy by 12 months. Maintenance therapy: Patients maintained on thiopurine monotherapy (14/35) vs. IFX/thiopurine therapy (15/35) were followed up. 2/15 (13\%) patients who received combination maintenance therapy underwent a colectomy at 12 months, compared with $1 / 14(7 \%)$ patients receiving thiopurine monotherapy $(p=0.610)$. Monitoring during maintenance: Post-discharge, thiopurine metabolites were monitored in 15/27 (56\%); faecal calprotectin in 11/32 (34\%); \& serum IFX levels in 4/20 (20\%). 20/32 (63\%) patients had an endoscopic evaluation after IFX salvage with median time to 1st endoscopy of 109 days (IQR 113-230). 
Conclusion: Following IFX induction therapy for ASUC, the uptake of maintenance therapy in this cohort \& strategies to monitor ongoing response were variable. These data suggest that the optimal maintenance \& monitoring strategy post IFX salvage therapy remains to be defined.

Keywords: Acute Severe Ulcerative Colitis, Maintenance Therapy, Monitoring, Infliximab, Thiopurine

\section{INTRODUCTION}

Patients with Acute Severe Ulcerative Colitis (ASUC), defined by Truelove and Witts' criteria, experience significant morbidity and undergo colectomy within 3 years in up to $60 \%$ of cases. $(1,2)$

The aim of treatment in the acute setting is induction of disease remission with intravenous corticosteroids and medical salvage therapies, such as Infliximab (IFX) or Cyclosporin. Clinical remission is achieved in 50 to $65 \%$ of patients at 1 year, following salvage therapy.(3) Patients who fail to respond adequately to medical management require an early colectomy; however, even those who achieve clinical remission with salvage therapy continue to be at high risk of disease relapse and surgical intervention.

In this patient group, ongoing maintenance therapy and close monitoring in the outpatient setting are necessary to prevent further exacerbations. At present, an optimal maintenance strategy following ASUC is yet to be established and longterm colectomy rates in clinical trials remain high. (3) 
Within the literature and current ECCO and ACG guidelines, there is minimal evidence to guide decision-making in this population in regards to: (i) individualised maintenance drug selection, (ii) monitoring strategy sensitivity in relation to clinical outcomes, and (iii) appropriate timing of outpatient surveillance. Maintenance therapies that are currently used in clinical practice include: 5-aminosalicylate (5-ASA) derivatives, thiopurines, methotrexate and biological agents - predominantly, infliximab and more recently, vedolizumab. (4-6) Combination therapy with IFX and a thiopurine has been proposed as a superior maintenance strategy, when compared to monotherapy with either agent(7); however, this has not been investigated in a prospective setting.

We performed this study to evaluate the maintenance and monitoring strategies employed following successful induction of remission in our cohort. Clinical and biochemical markers of treatment response were also investigated to assess and compare the efficacy of each maintenance therapy and the effect of monitoring on long-term outcomes.

\section{MATERIALS AND METHODS}

\section{Study Population}

This study consisted of a 12-month retrospective review of adult UC patients, admitted consecutively to six Melbourne IBD referral centres. All patients were hospitalised with ASUC as defined by Truelove and Witts' criteria. (8) Patients who received infliximab salvage therapy between April 2014 and May 2015 were eligible for inclusion. Patients who underwent urgent colectomy prior to salvage therapy initiation were excluded. Following successful induction of remission, maintenance and monitoring strategies were determined individually by treating clinicians and clinical outcomes were recorded for 12 months. 
Patients who underwent a colectomy within 3 months of initial presentation were deemed to have had an unsuccessful induction of remission and were excluded from the maintenance analysis.

\section{Outcome Measures}

The primary outcome was colectomy rate at 12 months. Secondary outcomes included utilisation of biochemical and endoscopic monitoring strategies. Biochemical monitoring consisted of therapeutic drug monitoring, where applicable - including thiopurine metabolites, serum infliximab trough levels, and faecal calprotectin levels. Endoscopic monitoring was defined as a flexible sigmoidoscopy or colonoscopy following induction of remission.

\section{Statistical Analysis}

Demographics, collected variables and treatment outcomes at 12 months in the respective maintenance treatment groups were compared using Chi-squared or Fisher's Exact tests. Continuous variables were analysed using (parametric) ttests and (non-parametric) Mann-Whitney tests for symmetrically and asymmetrically distributed data, respectively. Descriptive statistics included percentages and means and medians with interquartile ranges (IQR). Statistical analyses were performed using STATA Statistical Software (version 14, copyright (C) StataCorp 1985-2015). All p values were two-tailed and statistical significance was defined as $p \leq 0.05$.

\section{Ethics}

Ethics approval was obtained from the respective Human Research Ethics Committees of Austin Health, St Vincent's Hospital Melbourne, Alfred Health, Eastern Health, Melbourne Health and Monash Health. 


\section{RESULTS}

\section{Patient Population}

The study population consisted of 41 patients. One patient was lost to follow-up and five patients underwent a colectomy within 3 months of initial presentation. Following completion of IFX induction therapy, 2 of the remaining 35 patients (6\%) received scheduled infliximab maintenance only, 14/35 (40\%) received thiopurine monotherapy and 15/35 (43\%) were maintained on both IFX and thiopurine treatment. One patient was given 5-aminosalicylate monotherapy (3\%), two patients were maintained on IFX and methotrexate (MTX) (6\%) and one patient received IFX, MTX and tacrolimus (3\%). Infliximab maintenance infusions were initially administered at $5 \mathrm{mg} / \mathrm{kg}$ dosing. The distribution of maintenance therapies used is summarised in Figure 1.

Due to the significantly biased agent selection within this cohort, statistical analyses were limited to patients who received combination therapy with IFX and a thiopurine, and those who received thiopurine monotherapy.

Baseline demographics of the patients in these two groups are outlined in Table 1. Age, sex and disease duration were similar in both populations. Patients who received combination maintenance therapy had higher rates of hospitalisation for UC within the preceding 3 months $(p=0.242)$ and tended to be more likely to have had previous thiopurine exposure $(p=0.128)$; however, these differences did not reach statistical significance. Baseline CRP and albumin levels were comparable between the two groups, as was overall length of stay in hospital.

\section{Maintenance therapy}

This article is protected by copyright. All rights reserved. 
Within our cohort, six patients, who had completed IFX induction therapy and remained colectomy-free at 3 months, progressed to colectomy by 12-month follow-up. Clinical outcomes following induction of remission are outlined in Table 2 and Figure 2. Thirteen percent (2/15) of patients who received combination maintenance therapy underwent a colectomy between 3 and 12 months. In comparison, seven percent of those treated with thiopurine monotherapy (1/14) progressed to colectomy during the maintenance phase. One of the two patients managed with IFX and MTX had a colectomy; one of the two patients maintained on IFX monotherapy underwent colectomy also. The one patient who was maintained on 5-ASA monotherapy progressed to colectomy, while the one patient maintained on IFX, MTX and tacrolimus remained colectomy-free.

Two patients who had originally been commenced on thiopurine maintenance therapy developed flares of disease activity and were subsequently commenced on combination maintenance therapy (IFX plus thiopurine). In addition, two patients experienced a further episode of ASUC whilst receiving IFX maintenance therapy and were subsequently switched to vedolizumab, with one progressing to colectomy by 12 months.

There was no statistically significant difference in 12-month colectomy rate following combination IFX and thiopurine maintenance, and thiopurine monotherapy $(p=0.610)$. Median time to colectomy in the combination therapy group was 238 days (IQR 185-291) from last IFX induction infusion and 193.5 days (IQR 141-246) from 3 months post-admission. In the thiopurine monotherapy group, time to median colectomy was shorter, at 109 days from last IFX induction infusion and 26 days from 3 months post-admission $(p=0.949)$.

This article is protected by copyright. All rights reserved. 


\section{Monitoring in the maintenance phase}

The uptake of biochemical and endoscopic monitoring strategies in our cohort are outlined in Table 3. A total of 29 patients received thiopurine maintenance, either alone or in combination with other maintenance agents. Follow-up of thiopurine testing utilisation was not available for 2 patients. Fifty-six percent (15/27) were monitored with thiopurine metabolite testing as an outpatient. Faecal calprotectin monitoring was utilised in $11 / 32$ patients (34\%). The rate of therapeutic drug monitoring among patients who received IFX maintenance therapy was lower in comparison, with only 4/20 (20\%) undergoing serum IFX trough level testing. Endoscopy was performed in 20/32 patients (63\%) following induction of remission, with the median time to endoscopy being 119 days following initial presentation (IQR 113-230).

Numerically lower rates of colectomy were observed in patients who underwent thiopurine drug monitoring compared to those who did not (10\% vs. $13 \%$, respectively, $p=1.000$ ), None of the patients who underwent serum IFX monitoring progressed to colectomy at 12 months $(p=0.530)$ - this result, while not reaching statistical significance, is a clinically relevant finding. Of note, patients who underwent endoscopy progressed to colectomy at a numerically higher rate than those who were unmonitored $(p=0.066)$.

A total of 5 IFX trough levels were measured between 4 patients in our sample, with a median value of $3 \mathrm{ug} / \mathrm{mL}$. Infliximab dose escalation (increased from $5 \mathrm{mg} / \mathrm{kg}$ to $10 \mathrm{mg} / \mathrm{kg}$ ) was undertaken in one patient (5\%) and occurred in the context of ongoing disease activity with a subtherapeutic drug level (i.e. $<0.1 \mathrm{ug} / \mathrm{mL}$ ). The same patient underwent subsequent dose de-escalation and infusion interval lengthening once clinical remission had been achieved. Two patients received only one IFX infusion before experiencing symptom relapse that necessitated re-induction therapy. The majority of the remaining patients 
received 8-weekly maintenance IFX (12/18 - 67\%). Infliximab infusions were administered according to a number of different schedules, including - 6-weekly $(1 / 18-6 \%)$ and 2-weekly $(1 / 18-6 \%)$. Three patients received maintenance IFX at irregular intervals, ranging from 2 to 10-weekly, during the study period. No truncation of scheduled infusion intervals was observed.

\section{Adverse drug reactions}

Following IFX induction therapy, one patient developed acute cholecystitis, which has previously been described in association with IFX use(9-11); however, it was not clear as to whether IFX was the cause in the patient in our study. Another patient developed an axillary rash while receiving 8-weekly maintenance IFX, which settled with topical therapy. There were no other major side effects reported in this study.

\section{DISCUSSION}

This real-life cohort study is the first in the literature to focus on the use of maintenance therapy and monitoring strategies following successful IFX salvage for ASUC. Despite the known high risk of colectomy with ASUC, we found that the use of maintenance therapy following infliximab was highly variable and monitoring practices were ad hoc. This variability in practice highlights the fact that the optimal strategy maintenance therapy and monitoring strategy following successful induction therapy for ASUC is yet to be defined.

The maintenance strategies employed in our cohort varied to such an extent that only a limited analysis could be undertaken despite multicentre involvement in this study. We observed a bias toward the use of thiopurine maintenance, either in combination with IFX or as monotherapy, in those who were thiopurine 
naive compared to the use of infliximab in those who were thiopurine experienced, despite limited data to support either approach. The heterogeneity of these results most likely reflects the current lack of evidence-based data to inform clinical decision-making regarding the optimal maintenance strategy.

Previous studies evaluating salvage therapy in ASUC have focused on induction therapy whereas the optimal maintenance strategy following induction remains unclear. Although a recent retrospective study indicated a significant improvement in colectomy rates out to 1 month between those receiving accelerated vs. standard induction therapy with infliximab, there was no significant difference between the two groups at 2 years, suggesting a failure of maintenance therapy. (12) Maintenance of remission with IFX has demonstrated efficacy in chronic active colitis and concomitant therapy with IFX and a thiopurine has been associated with a lower colectomy rate. $(6,7)$ However, to our knowledge, few studies have specifically explored the role of maintenance therapy following ASUC. Two large multicentre prospective trials CySIF(13) and the more recent CONSTRUCT(14), evaluated clinical outcomes at 3 months and 3 years following ASUC, respectively. Patients in the CySIF study, who demonstrated clinical response at 1 week following salvage therapy, received azathioprine maintenance therapy; maintenance care in the CONSTRUCT study was unregulated beyond 3 months, receiving a combination of thiopurines and/or methotrexate in the maintenance phase. Five-year follow-up of patients from the CySIF trial identified disease relapse in $35 \%$ of patients $(9 / 26)$ who had primary response to infliximab salvage therapy (defined by symptom recurrence beyond 3 months) and 38\% of patients (9/24) of those who had primary response to cyclosporin. (15) A variety of regimens ranging from topical therapies to oral 5-ASA, thiopurines and monoclonal antibodies have been used as maintenance therapies in published studies with limited data to support their efficacy. 
Following induction therapy, 20/35 patients (57\%) were commenced on maintenance infliximab, either alone or in combination with other maintenance agents. The remaining 15/35 patients (43\%) discontinued infliximab and instead received ongoing treatment with a thiopurine or 5-ASA.

Factors influencing choice of maintenance therapy in our study included: (1) the discretion of the treating gastroenterologist at each respective centre; (2) the availability of scheduled maintenance IFX therapy via the Pharmaceutical Benefits Scheme (PBS) of Australia whereby scheduled maintenance therapy was only available for patients with chronic active UC which has been refractory to thiopurines, aminosalicylates and steroids for $>3$ months, and (3) the provision of maintenance infliximab via a Pharmaceutical compassionate access program for a small subset of patients at the discretion of the treating physician.

Previous thiopurine experience has been proposed as an indication for maintenance infliximab; however, this did not appear to influence maintenance selection in this study. Half of the patients who received maintenance IFX were thiopurine-naïve (10/20); notably, one of the two patients who received concomitant IFX and methotrexate was thiopurine-naïve. Combination IFX, methotrexate and tacrolimus was used in a patient who had previous thiopurine experience. In our study there was no significant difference in outcome between those on thiopurine maintenance therapy versus those on combination IFX and thiopurine; however, we acknowledge that larger studies are required to investigate the optimal maintenance strategy.

Utilisation of biochemical and endoscopic monitoring following induction of remission was variable in our cohort, despite evidence suggesting that these 
methods of surveillance are useful in evaluating loss of therapeutic response. (16) Although undertaken in patients with chronic active UC, a post-hoc analysis of the ACT1/2 trials found that higher median infliximab concentrations measured at weeks 8, 30 and 54 following IFX induction, were associated with higher rates of clinical response, remission and mucosal healing. (17) Infliximab drug monitoring was not routinely undertaken in our cohort. Nonetheless recent evidence indicates that patients with UC are more likely to require dose adjustment compared to patients with Crohn's disease with a median time to dose optimisation of 7 months (95\% confidence interval [Cl] 4.8-9.2) in UC and 27 months [95\% Cl 7.3-46.7] in CD, $p=0.00003$. (18) On this basis, it is likely that therapeutic drug monitoring is of benefit in the maintenance phase, following successful induction of remission in ASUC; however, the value of therapeutic drug monitoring during maintenance care requires prospective evaluation.

Higher rates of colectomy were observed in patients who underwent endoscopy compared to those who did not, suggesting that objective monitoring in these cases was performed reactively in response to clinical deterioration rather than monitoring being proactively applied to all patients as part of routine clinical assessment. A similar trend was observed in a dual-centre audit of thiopurine metabolite monitoring in IBD, in which $79 \%$ of thiopurine testing was performed in response to active disease. (19) Overall, our study identifies a lack of standardisation in clinical practice, beyond the acute hospital setting of severe UC and emphasises the need to find the optimal monitoring strategy.

Limitations of this study include its retrospective design and relatively small sample size. The heterogeneity of maintenance therapy administered in our cohort, restricted statistical analysis and findings are largely descriptive in 
nature as a result. Moreover, analysis of the efficacy of each maintenance drug regimen, with respect to colectomy rate, was not possible due to the small number of subgroup subjects. Disease activity was not recorded uniformly across all centres - as such, disease activity and remission rates during the study period were not analysed.

The recent STRIDE guidelines recommend the use of standardised treat-totarget strategies in Ulcerative Colitis, with clinical assessment that is corroborated with objective measures of disease activity such as surveillance endoscopy 3-6 months after treatment initiation and adjunct monitoring of biomarkers such as CRP and Faecal Calprotectin.(20) Such an approach is particularly pertinent following successful induction for acute severe ulcerative colitis, given that recurrence of acute severe colitis may occur in up to $36 \%$ of patients following their first episode. (21) The detection of subclinical disease may afford the opportunity to step-up therapy to avoid disease progression to the point of symptom relapse.

\section{CONCLUSION}

Although the focus of management of ASUC has been on induction of remission with salvage therapy, our data suggest that attention must also be given to the maintenance of remission in order to improve disease outcomes. The optimal maintenance strategy needs to be defined based on treatment experience and clinical markers of disease course until predictive biomarkers are available to guide therapeutic selection. Well-designed prospective studies evaluating different maintenance strategies are now required in order to find the optimal maintenance strategy and approach to monitoring following successful induction for ASUC. 


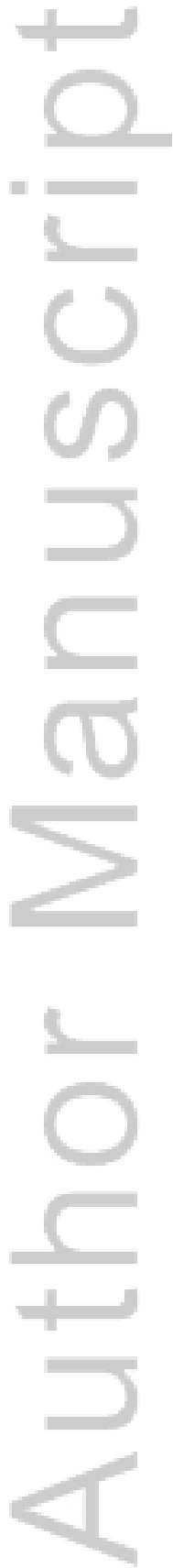

This article is protected by copyright. All rights reserved. 


\section{REFERENCES}

1. Actis GC, Fadda M, David E, Sapino A. Colectomy rate in steroid-refractory colitis initially responsive to cyclosporin: a long-term retrospective cohort study. BMC gastroenterology. 2007;7:13.

2. Gustavsson A, Jarnerot G, Hertervig E, Friis-Liby I, Blomquist L, Karlen P, et al. Clinical trial: colectomy after rescue therapy in ulcerative colitis - 3-year follow-up of the Swedish-Danish controlled infliximab study. Alimentary pharmacology \& therapeutics. 2010;32(8):984-9.

3. Seah D, De Cruz P. Review article: the practical management of acute severe ulcerative colitis. Alimentary pharmacology \& therapeutics. 2016;43(4):482-513.

4. Bickston Stephen J, Behm Brian W, Tsoulis David J, Cheng J, MacDonald John K, Khanna $\mathrm{R}$, et al. Vedolizumab for induction and maintenance of remission in ulcerative colitis. Cochrane Database of Systematic Reviews [Internet]. 2014; (8). Available from: http://onlinelibrary.wiley.com/doi/10.1002/14651858.CD007571.pub2/abstract http://onlinelibrary.wiley.com/store/10.1002/14651858.CD007571.pub2/asset/CD007 571.pdf? $v=1 \& \mathrm{t}=\mathrm{i} 020 \mathrm{c} 7 \mathrm{wj} \& \mathrm{~s}=853254 \mathrm{a410588f97fd9146b13ede98c184c0f793.}$.

5. Carbonnel F, Colombel JF, Filippi J, Katsanos KH, Peyrin-Biroulet L, Allez M, et al. Methotrexate Is Not Superior to Placebo for Inducing Steroid-Free Remission, but Induces Steroid-Free Clinical Remission in a Larger Proportion of Patients With Ulcerative Colitis. Gastroenterology. 2016;150(2):380-8.e4.

6. Rutgeerts P, Sandborn WJ, Feagan BG, Reinisch W, Olson A, Johanns J, et al. Infliximab for induction and maintenance therapy for ulcerative colitis. The New England journal of medicine. 2005;353(23):2462-76.

7. Panaccione R, Ghosh S, Middleton S, Marquez JR, Scott BB, Flint L, et al. Combination therapy with infliximab and azathioprine is superior to monotherapy with either agent in ulcerative colitis. Gastroenterology. 2014;146(2):392-400.e3.

8. Truelove SC, Witts LJ. Cortisone in ulcerative colitis; final report on a therapeutic trial. British medical journal. 1955;2(4947):1041-8.

9. Foeldvari I, Kruger E, Schneider T. Acute, non-obstructive, sterile cholecystitis associated with etanercept and infliximab for the treatment of juvenile polyarticular rheumatoid arthritis. Annals of the rheumatic diseases. 2003;62(9):908-9.

10. Patel TR, Patel KN, Boyarsky AH. Staphylococcal liver abscess and acute cholecystitis in a patient with Crohn's disease receiving infliximab. Journal of gastrointestinal surgery : official journal of the Society for Surgery of the Alimentary Tract. 2006;10(1):105-10.

11. Song MS, Lee SB, Sohn S, Oh JH, Yoon KL, Han JW, et al. Infliximab treatment for refractory kawasaki disease in korean children. Korean circulation journal. 2010;40(7):334-8. 
12. Gibson DJ, Heetun ZS, Redmond CE, Nanda KS, Keegan D, Byrne K, et al. An Accelerated Infliximab Induction Regimen Reduces the Need for Early Colectomy in Patients With Acute Severe Ulcerative Colitis. Clinical gastroenterology and hepatology : the official clinical practice journal of the American Gastroenterological Association. 2014.

13. Laharie D, Bourreille A, Branche J, Allez M, Bouhnik Y, Filippi J, et al. Ciclosporin versus infliximab in patients with severe ulcerative colitis refractory to intravenous steroids: a parallel, open-label randomised controlled trial. Lancet. 2012;380(9857):1909-15.

14. Williams JG, Alam MF, Alrubaiy L, Arnott I, Clement C, Cohen D, et al. Infliximab versus ciclosporin for steroid-resistant acute severe ulcerative colitis (CONSTRUCT): a mixed methods, open-label, pragmatic randomised trial. The lancet Gastroenterology \& hepatology. 2016;1(1):15-24.

15. Laharie D, Bourreille A, Branche J, Allez M, Bouhnik Y, Filippi J, et al. Long-term outcome of patients with steroid-refractory acute severe UC treated with ciclosporin or infliximab. 2017.

16. Seow CH, Newman A, Irwin SP, Steinhart AH, Silverberg MS, Greenberg GR. Trough serum infliximab: a predictive factor of clinical outcome for infliximab treatment in acute ulcerative colitis. Gut. 2010;59(1):49-54.

17. Adedokun OJ, Sandborn WJ, Feagan BG, Rutgeerts P, Xu Z, Marano CW, et al. Association between serum concentration of infliximab and efficacy in adult patients with ulcerative colitis. Gastroenterology. 2014;147(6):1296-307.e5.

18. O'Donnell S, Stempak JM, Steinhart AH, Silverberg MS. Higher Rates of Dose Optimisation for Infliximab Responders in Ulcerative Colitis than in Crohn's disease. Journal of Crohn's \& colitis. 2015;9(10):830-6.

19. Goldberg R, Moore G, Cunningham G, Schulberg J, Marsh P, Brown S, et al. Thiopurine metabolite testing in inflammatory bowel disease. Journal of gastroenterology and hepatology. 2016;31(3):553-60.

20. Peyrin-Biroulet L, Sandborn W, Sands BE, Reinisch W, Bemelman W, Bryant RV, et al. Selecting Therapeutic Targets in Inflammatory Bowel Disease (STRIDE): Determining Therapeutic Goals for Treat-to-Target. The American journal of gastroenterology. 2015;110(9):1324-38.

21. Dinesen LC, Walsh AJ, Protic MN, Heap G, Cummings F, Warren BF, et al. The pattern and outcome of acute severe colitis. Journal of Crohn's \& colitis. 2010;4(4):431-7.

This article is protected by copyright. All rights reserved. 


\section{TABLES}

Table 1: Baseline demographics.

\begin{tabular}{|c|c|c|c|}
\hline 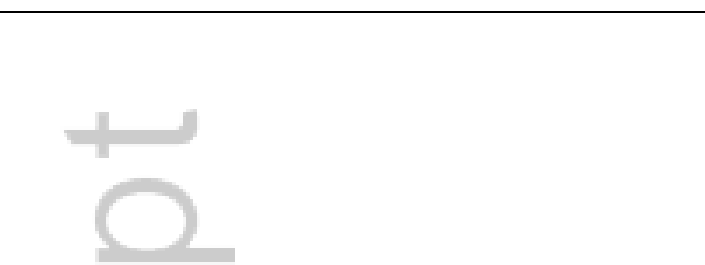 & $\begin{array}{l}\text { Combination } \\
\text { maintenance } \\
\text { therapy - IFX \& } \\
\text { thiopurine (15/35) }\end{array}$ & $\begin{array}{l}\text { Thiopurine } \\
\text { maintenance } \\
\text { therapy only } \\
(14 / 35)\end{array}$ & P-value \\
\hline Female, n (\%) & $8(53.55)$ & $3(21.43)$ & 0.128 \\
\hline Age & $\begin{array}{l}33.87 \quad(28.13- \\
44.17)\end{array}$ & $\begin{array}{l}32.50 \quad(23.34- \\
36.33)\end{array}$ & 0.582 \\
\hline $\begin{array}{l}\text { Disease duration (months), median } \\
\text { (IQR) }\end{array}$ & $37(15-79)$ & $30(25-45)$ & 0.713 \\
\hline Prior hospitalisation for UC flare, n (\%) & $5(45.45)$ & $6(46.15)$ & 1.000 \\
\hline $\begin{array}{l}\text { Hospitalisation within last } 3 \text { months, } n \\
\text { (\%) }\end{array}$ & $4(80.00)$ & $2(33.33)$ & 0.242 \\
\hline \multicolumn{4}{|l|}{ Previous medications } \\
\hline $\begin{array}{l}\text { Previous/concomitant 5-ASA use on } \\
\text { admission, } \mathrm{n}(\%)\end{array}$ & $10(71.43)$ & $10(71.43)$ & 1.000 \\
\hline Thiopurine exposure, $\mathrm{n}(\%)$ & $8(53.33)$ & $3(21.43)$ & 0.128 \\
\hline $\begin{array}{l}\text { CRP on admission }(\mathrm{mg} / \mathrm{L}), \text { median } \\
(\mathrm{IQR})\end{array}$ & $35(7-85)$ & $43.5(20-124.9)$ & 0.808 \\
\hline $\begin{array}{l}\text { Albumin on admission }(\mathrm{g} / \mathrm{L}), \text { median } \\
\text { (IQR) }\end{array}$ & $29.5(26-34)$ & $31(27-34)$ & 0.695 \\
\hline $\begin{array}{l}\text { CRP/Albumin ratio on admission, } \\
\text { median (IQR) }\end{array}$ & $1.57(0.21-4.51)$ & $1.31(0.61-4.45)$ & 0.959 \\
\hline CRP on induction (mg/L), median (IQR) & $14(5-34)$ & $26(6-46.7)$ & 0.496 \\
\hline $\begin{array}{l}\text { Albumin on induction }(\mathrm{g} / \mathrm{L}) \text {, median } \\
(\mathrm{IQR})\end{array}$ & $21(6-43)$ & $23(22-30)$ & 0.741 \\
\hline $\begin{array}{l}\text { CRP/Albumin ratio on induction, median } \\
\text { (IQR) }\end{array}$ & $0.75(0.32-3.42)$ & $0.19(0.06-0.68)$ & 0.157 \\
\hline Duration of admission (d), median (IQR) & $8(7-13)$ & $10.5(7-12)$ & 0.538 \\
\hline
\end{tabular}

This article is protected by copyright. All rights reserved. 
Table 2: Clinical outcomes in the maintenance phase ( $\geq 3$ months) following successful induction of remission.

\begin{tabular}{|r|l|}
\hline Maintenance regimen & Colectomy rate at 12 months \\
\hline Infliximab plus thiopurine & $13 \%(2 / 15)$ \\
\hline Infliximab plus methotrexate & $50 \%(1 / 2)$ \\
\hline Infliximab plus methotrexate plus & $0 \%(0 / 1)$ \\
tacrolimus & \\
\hline Thiopurine only & $7 \%(1 / 14)$ \\
\hline Infliximab only & $50 \%(1 / 2)$ \\
\hline $5-A S A$ only & $100 \%(1 / 1)$ \\
\hline Overall & $17 \%(6 / 35)$ \\
\hline
\end{tabular}

This article is protected by copyright. All rights reserved. 
Table 3: Utilisation of monitoring strategies following successful induction of remission.

\begin{tabular}{|l|l|l|l|l|}
\hline $\begin{array}{l}\text { Monitoring } \\
\text { strategy }\end{array}$ & $\begin{array}{l}\text { Total patients } \\
\text { monitored, } \mathbf{n} \\
\mathbf{( \% )}\end{array}$ & $\begin{array}{l}\text { Colectomy rate } \\
\text { in monitored } \\
\text { cohort, n (\%) }\end{array}$ & $\begin{array}{l}\text { Colectomy rate } \\
\text { in unmonitored } \\
\text { cohort, n (\%) }\end{array}$ & P-value \\
\hline $\begin{array}{l}\text { Thiopurine } \\
\text { metabolites }\end{array}$ & $15(56)$ & $2(13)$ & $1(10)$ & 1.000 \\
\hline $\begin{array}{l}\text { Faecal } \\
\text { calprotectin }\end{array}$ & $11(34)$ & $2(18)$ & $4(20)$ & 1.000 \\
\hline $\begin{array}{l}\text { Serum IFX } \\
\text { Endoscopy (e.g. } \\
\text { flexible } \\
\text { sigmoidoscopy } \\
\text { or colonoscopy) }\end{array}$ & $20(63)$ & $6(30)$ & $4(25)$ & 0.538 \\
\hline
\end{tabular}




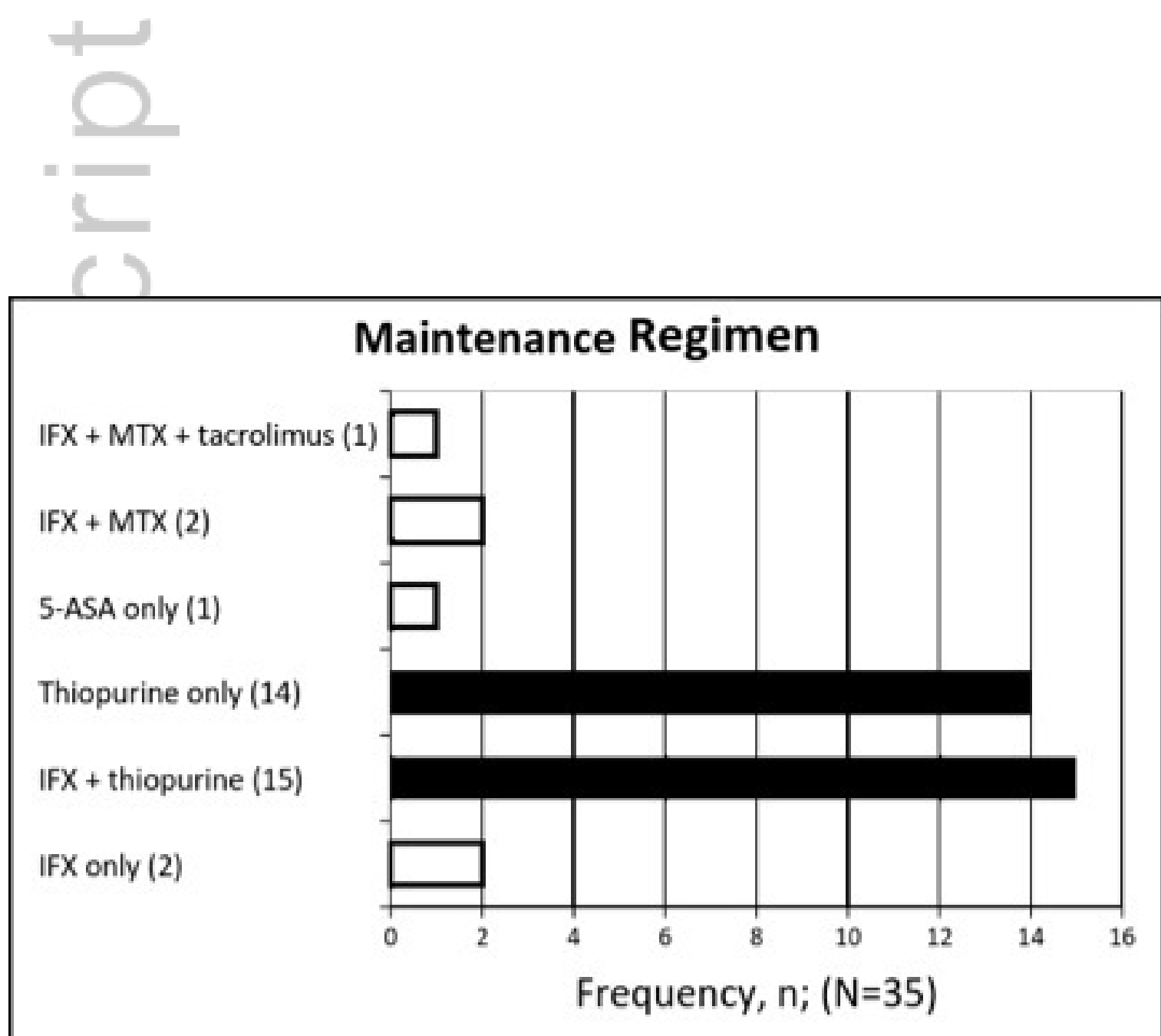

JGH_13850_F1.jpg 


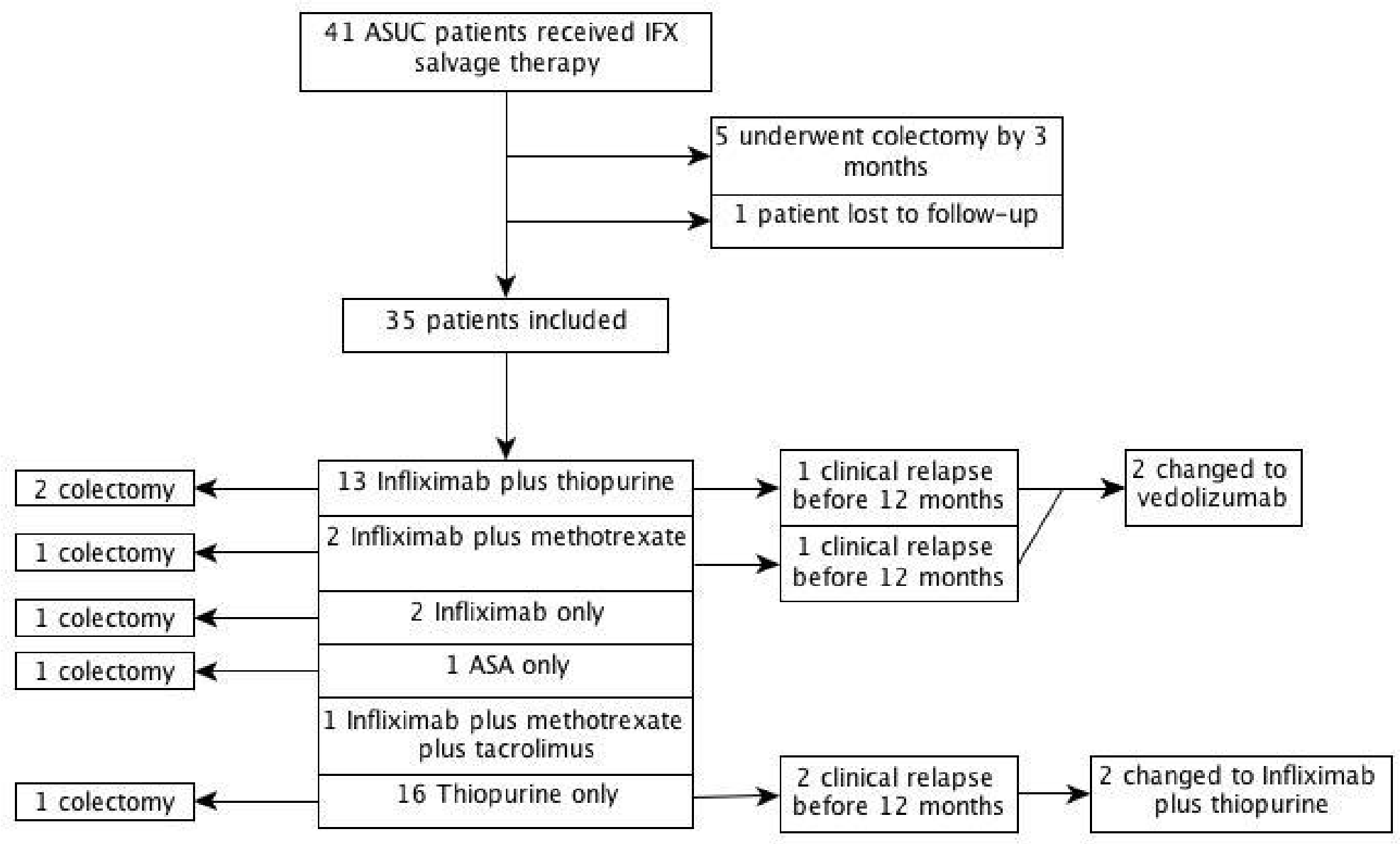

JGH_13850_F2.jpg

This article is protected by copyright. All rights reserved. 


\section{University Library}

\section{- M M N E R VA A gateway to Melbourne's research publications}

Minerva Access is the Institutional Repository of The University of Melbourne

Author/s:

Seah, D;Choy, MC;Gorelik, A;Connell, WR;Sparrow, MP;Van Langenberg, D;Hebbard, G;Moore, G;De Cruz, P

Title:

Examining maintenance care following infliximab salvage therapy for acute severe ulcerative colitis

Date:

2018-01-01

Citation:

Seah, D., Choy, M. C., Gorelik, A., Connell, W. R., Sparrow, M. P., Van Langenberg, D., Hebbard, G., Moore, G. \& De Cruz, P. (2018). Examining maintenance care following infliximab salvage therapy for acute severe ulcerative colitis. [Abstract]. JOURNAL OF GASTROENTEROLOGY AND HEPATOLOGY, 33 (1), pp.226-231. https://doi.org/10.1111/ jgh. 13850.

Persistent Link:

http://hdl.handle.net/11343/294089 